\title{
Cost Management in Construction Projects: Rework and Its Effects
}

\author{
Mohammad Miri \\ Member faculty of Engineering Department, Velayat University, Iranshahr, Iran \\ Email:m.miri@velayat.ac.ir \\ Mahsa Khaksefidi \\ Member faculty of Engineering Department, Velayat University, Iranshahr, Iran \\ Email:m.khaksefidi@velayat.ac.ir
}

\section{Doi:10.5901/mjss.2015.v6n6s6p209}

\section{Abstract}

In Iran, a lot of money spent annually on construction projects, in the form of construction and non-construction projects. One of the serious shortcomings of the management construction in the country, is absence of a specified system for recording the actual costs of various activities. Project cost management is an activity which deals forecasting, planning, control, cost finding, analysis and assessment. When you realize cost management performance tangibly, as a result of mismanagement, lack of financial resources appears in all the components of project. In this situation, managers can be effective support to keep track of rework events and play an important role on the performance and efficiency of projects. Rework has opposite effect on the cost and timing of projects and satisfaction of people. Numerous studies have been carried out to quantify the cost of rework projects. Among the causes of reworking we can mention the factors related to customers, factors related to the design and factors related to subcontractors. This paper examines the construction cost management and the role of rework. Basic topics in management costs are presented and rework factors discussed in detail and finally refer to the appropriate methods for identifying and managing rework to reduce the total cost of construction projects.

Keywords: cost management, project management, Rework, construction projects

\section{Introduction}

According to the Central Bank of the Islamic Republic of Iran, investment and construction activities of the private sector in urban areas in different provinces of Iran in the first half of year 2004, was 416,552,586 Rials. Which increase $53.1 \%$ over the previous year and the cost of a square meter basis of completed buildings was 6,020,544 Rials that increase $22 \%$ compared to the same period last year (cbi.ir website). In fact, most of the plans and projects in our country are accomplished due to various factors of time and cost over time and budget and predetermined (regardless ofcontinuous and sequential inflation). Unfortunately, in terms of cost control and identify cost waste serious work has not been done so far in our country. Rework during manufacturing is the most important factor for waste of resources in order to track the impact of problems on cost and time of project, it is essential that accurate information from the project be available. Therefore, existence of a systematic and organized process to collect performance data, and provided clear rules in the project management process is necessary (Jarkas, Bitar, 2012). Project performance report should include the following:

1. Containing information about the scope, schedule, cost and quality of the project.

2. Provide comprehensive analysis and prevents the costs and timing of the project.

3. Estimate the time and budget needed to complete the project by using the results.

4. Based on it we can do precise control about the time and cost of the project.

If the allocated budget is used to measure the performance of cost, the allocated funds to an activity cannot be changed arbitrarily, when it is determined that the budget is not enough for the project. Worse is when the ongoing activities budget is spent on the current activities. This issue solve the problem of lack of funds as cross-sectional but lack of capital show itself when it is too late to rectify. Three costs associated with the construction defined as: costs associated with subcontractors, coordination and planning cost and the cost of construction and the three categories of non-compliance which has the most frequency: the reasons for the design, construction and reasons of subcontractors (Peter, Lovea \& Zahir Irani, 2003). In this article, the definition of cost management and its components will be discussed. Then determine the cost of construction and point out to rework that arise during construction. Based on factors related to 
rework and to determine how to manage the costs of rework will be mentioned. Review of rework is used to reduce costs and taxes in construction projects. Identify and control of rework causes the reduction of construction cost and decrease the lesions associated with the partners and owners of houses and increases people satisfaction.

\section{Cost Management}

Project Cost Management is a management activity that deals with forecasting, planning, control, cost finding, analysis and evaluation of the contractors and it is used to control project cost (Zhen, 2008). Organizations that are active in many different projects very interested in accurately estimate project costs. Contractors proposed an amount for each project, and after winning it should be implement based on funds in the tender. So it is very important for them to offer an amount that cover reasonable share overhead, and meet intended profit. And on the other hand the price can compete with other prices. Project cost management performance when understood tangibly that due to improper management of early cost it appear on all components of the project. Even in the new planning techniques such as Rolling Wave Planning, even the smallest changes in each component of the project will impact on the cost and vice versa (Jergeas \& Ruwanpura, 2010). Based on XU Bing approach in the management of project construction cost, it is necessary that the timing of the project is done by considering the actual cost and the estimated cost of the project (XU Bing, 2009). Figure 1 is a schematic, showing how to manage construction projects.

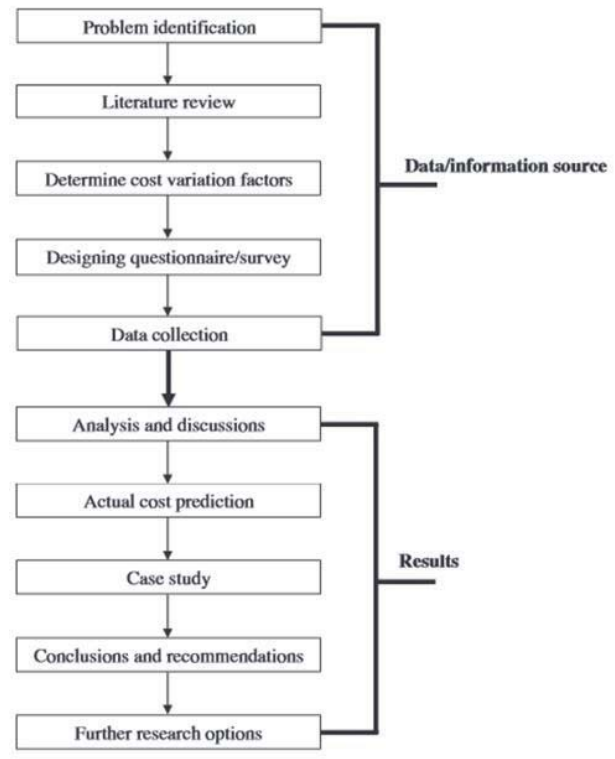

Figure 1. Construction Project Cost Management Process

From the standard perspective PMBOK, cost management consists of four arguments that are hierarchically associated with each other that include resource planning, cost estimating, cost budgeting and cost control (Project Management Institute, 2004). Each of these cases consists of three parts: input, processing and output and the output of each section is the input of next section. Resource planning determine resources, including manpower, materials, equipment, and their number in order to complete each of the project's activities.Cost estimates, estimates from the costs of the resources needed to complete project activities which are associated with uncertainty. The degree of uncertainty in every phase of construction project is different. Figure 2 shows degrees of uncertainty in various phases of construction projects. According to this figure the feasibility studies of the project have greatest variations (Antohie, 2009). In the process of cost budgeting the total estimated cost for the project is allocated separately to each of the project activities so that the basis for the cost to be defined.Following the project, obtained base is used to measure project effectiveness. Cost control include identifying changes in the cost of the project, change management and evaluation of changes occurring at 
the moment of acceptance of changes. For this purpose, you need to control cost performance to identify potential disorders and avoided incorrect changes in costs. The cost control is a key activity, which consists of 5 steps:

1. Determine the desired cost that project costs are controlled under that base.

2. Calculate the real cost based on planned project

3. Comparison of the real cost and the cost of the project

4. Analysis of the level, degree of effects and cause of deviations

5. Recommend ways to correct operation

Project Cost Management includes the processes required to ensure that projects are completed based on budget. For this reason, introduced steps puts appropriate way to management that achieving the lowest cost and time spent on the project be feasible.

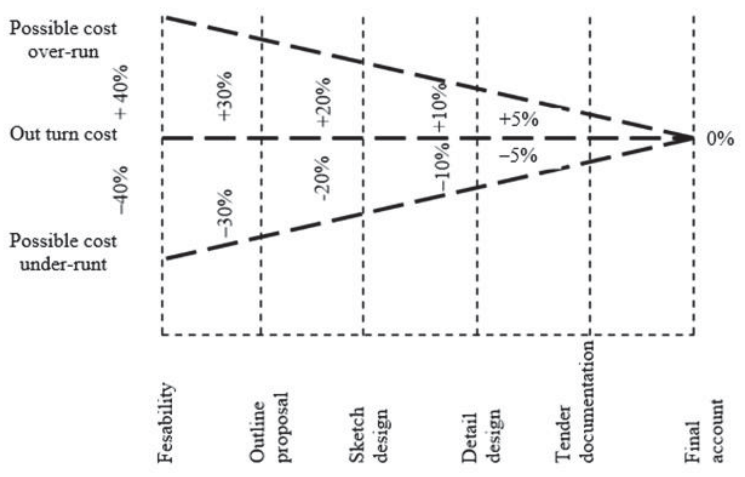

Figure 2. The degree of uncertainty in construction projects

\section{Construction Costs}

One of the serious shortcomings in the field of construction management in country is failure to set up a system for recording the actual cost of certain different activities during implementing tasks. Each company to estimate its profit and loss during the project implementation creates a method but as long as these methods are not systematic and principled, always there is the danger of forgetting or neglecting some costs and responsible may face with unexpected and often harsh results. Project costs include the cost of sub-projects, the cost of current issues in project other costs available at project, costs stipulated in the agreement and tax (Hang Xiaojian \& Ni Zirong, 2005) which is described in detail in Table 1.

Table 1. Classification of construction project costs

\begin{tabular}{|l|l|}
\hline Cost title & Description \\
\hline Sub projects costs & $\begin{array}{l}\text { Labor costs, raw material costs, costs of construction machines in the project, investor managers rights, benefits and costs } \\
\text { of risk }\end{array}$ \\
\hline Current projects cost & $\begin{array}{l}\text { The cost of environmental protection facilities, the cost of security systems, facility cost of heating (thermal), the cost of the } \\
\text { building at night,Relocation costs, construction costs and the winter rainy season, the location of this equipment and large } \\
\text { machinery ,The cost of setting up and installing the equipment, the cost of drainage construction costs spent to accelerate } \\
\text { construction, the cost of building thermal coatings Protection of labor and equipment costs has been completed, the work } \\
\text { and the cost of protecting and strengthening the concrete forms, scaffolding costs, the cost of lifting equipment }\end{array}$ \\
\hline Other costs & $\begin{array}{l}\text { Temporary costs, estimated prices temporarily (temporary price estimate, evaluate prices estimated by the engineers), the } \\
\text { cost of daily living, the cost of public services to contract }\end{array}$ \\
\hline $\begin{array}{l}\text { Cost cases stipulated } \\
\text { in the contract }\end{array}$ & $\begin{array}{l}\text { The cost of clean-up and removal of waste products from campus site, value per share, a premium, domestic investment, } \\
\text { the project sudden accident insurance }\end{array}$ \\
\hline Tax & Business tax, maintenance tax, and urban construction \\
\hline
\end{tabular}

Each of the above issues is considered as a cost in the construction project, but in most cases because of the wrong actions, require that some activities be repeated. This has led that in addition to the cost which initially allocated to activities, other costs be considered to fix the defects. 


\section{Rework in Construction Projects}

Rework in construction projects refers to unessential activities associated with process or activity that has been in place from the beginning and require to be redone (Love, 2002). Based on Love \& Li in 2000 the qualitative failures are obvious characteristics of available activities at the construction. As Low \& Yeo was proved in 1998 by the implementation comprehensive quality management, cost of rework can even reach to zero, but avoid errors is not completely possible. In some extents, the level of rework in construction projects dependent on external factors such as high work capacity and market conditions. It means increase in defects and poor job performance might be due to lack of subcontractors access to skilled workers or additional pressure to complete the work faster (Kazaz, Birgonul \& Uiuberyli ,2005) Or is the result of internal factors such as errors, omissions, changes, poor coordination and poor communication between departments (Palaneeswaran, 2006). Rework has opposite effect on the performance and efficiency of the building and decrease its profit margins. The effects of rework can be mentioned as following:

1. Additional time to rework

2. Additional costs to remove duplication

3. Additional materials spent on rework and control next waste

4. The additional labor for rework

5. The difficulty of managing human resources

Previous studies indicate that the cost of rework in poor project management can be up to $25 \%$ of the contract value and $10 \%$ of the total cost of the project. For example, according to gathered information more than $30 \%$ of construction works related to rework. According to estimation of industry Institute of America annually amounts that lose due to rework is about $\$ 15$ million in construction projects (CII , 2001). Rework in a specific part cause to waste of time and reaching to the schedule which will ultimately increase costs. Rework also increase the complaints due to additional costs. For example, contractors guarantee various types of compensation that think is possible to them and this cause additional costs to be incurred (Fayek Aziz, 2013). Many studies have been done in order to quantify the cost of rework in construction engineering projects that in Table 2 some of them are mentioned. Unfortunately, some of the reworking factors, alternatively, are repeated in projects and project managers are unaware of it. Therefore identification of factors affecting the rework and control them is an important step towards reducing the cost of construction.

Table 2. Examples of studies conducted on the construction rework

\begin{tabular}{|l|l|}
\hline 1999 & According to a survey in construction projects in Sudan rework percentage is estimate between $2.3 \%$ to $9.4 \%$ of entire project value \\
\hline 1999 & According to studies was conducted in several construction projects in Australia rework of the entire project was estimated value of less than $10 \%$. \\
\hline 2000 & $\begin{array}{l}\text { Based on studies uk downtime costs on projects classified in two categories: } 1 \text {. The cost of rework that } 16 \% \text { of the project value, and (2) the cost of } \\
\text { delay that } 7 \% \text { of the project value will be spent on it. So about } 23 \% \text { of the value of the project mismanagement has imposed additional costs. }\end{array}$ \\
\hline 2002 & Costs of rework in research conducted in Sudan between 6 and $9.3 \%$ of the value of the project \\
\hline 2003 & 108 cases of rework in Canada about $61.65 \%$ and 3\% of engineering problems related to management issues, leadership and timing of construction. \\
\hline 2004 & According to a study in Australia the average cost of rework in projects without a quality management system contract value is $6.5 \%$ \\
\hline 2006 & According to a study conducted in Australia average cost of rework is about $5.5 \%$ of the total value of the contract \\
\hline 2006 & According to studies conducted in Hong Kong, the average cost of rework was about $10 \%$ of the total value of construction projects. \\
\hline
\end{tabular}

\section{Rework Factors in Construction}

Root causes of rework can be classified in different groups, such as factors related to customers, related factors to design and factors related to the subcontractors (Love, 2002. Rework assumptions related to the customer is related to design and construction such as design changes are done according to customer demand. Rework factors related to customer include:

1. The lack of experience and knowledge about the manufacturing process

2. Lack of funding is needed for the policy making of site.

3. The client is not involved in the project

4. Summary of things as inadequate

5. Poor communication with design consultants

6. Inadequacy of the literature of the contract.

Rework assumptions related to design including changes made by different groups such as customers, contractors and subcontractors and final consumers. Factors related to the design include:

1. Ineffective use of quality management requirements 
2. Ineffective use of information technology

3. Poor coordination between the various members of the design team

4. Timing / fixed time to complete each task

5. Poor planning time per worker

6. The lack of labor to complete the required tasks

7. Time surplus of workers / reallocation of time for other activities, projects

8. Stripped down design that makes time not considered sufficient.

9. Summary of the literature which is determined related to the customer based on the contract.

Factors associated with subcontractors that may cause rework include:

1. Weak labor

2. Inadequate management skills

3. The use of poor quality materials

4. Problems associated with other contractors and lack of coordination between them

5. Changes in construction methods to improve construction processes

6. Injuries, defects and errors related to poor construction methods

7. Restrictions in many activities and tasks

Rework has an important role in the implementation of the project. In fact, the effect of time is considered to repair defects in quality. Eliminate rework want more time to do things right from the beginning. Additional time will cause:

1. Contractor accelerates its work and therefore can complete the desired tasks according to schedule.

2. Due to the increasing the time, don't reach to the planned day.

In both cases, it is necessary that extra cost to speed up or delay the delivery to the customer that in the second case, the effect of defective repair work, is obvious in the cost of contractor quality. The timing of rework compensation related to the failure of building, design errors and other discrepancies of control, reverse effects of rework on time and costs is critical. Systematic literature to review related measurements with subcontractors is essential. According to the above issues, if detailed written not available, large amounts of rework costs (part of indirect costs) may not be reviewed.

\section{Rework Management}

Critical tasks of project managers is balancing the competing demands for quality, scope, time and cost. Project managers can be effective support to keep track of events related to rework and applying the effective management, to reduce the impact that the project has an important impact on performance and productivity (Hwang \& Zhao, 2014). There are different strategies in the management of the construction industry:

1. The use of appropriate mechanisms for risk in the supply chain ( i.e. sharing / travel / pricing of risks)

2. Considering compensation revisions of other sectors, such as construction complaints

Nowadays many new approaches to management (ie, partnership, associated contracts, supply chain management) is widely used as parts of a reinforcement project and is used as a systematic approach to explore the reasons for the rework. Figure 3 offers the basic framework for the reworking control. The basic reaction of this management framework include:

1. Definition of rework events

2. Systematic mapping used for classification.

3. Identify them based on category of rework

4. Accountability in cases of rework event

5. The estimates of the effects (ie on costs, time and customer satisfaction)

6. Assessment of compensable items for example for contracts complaints and reviewing from subcontractors

7. Registration of lessons for learning knowledge management market

Uncontrollable rework events in construction projects have serious impact on the performance of the project. However, native rework events should not considered as inevitable issues. Actually undesirable costs associated with rework can be improved and this work is applicable with the development of appropriate knowledge and structured system for managing rework. In projects that are poorly managed net impact of rework (the direct and indirect effects) can reduce the expected benefit margin significantly. On the other hand major impact on other tasks and various aspects of the project. Any rework problem that is diagnosed late or not diagnosed at all can be serious for home owners in construction project. A lot of duplication in construction projects due to lack of coordination in the management of various sectors, for example, lack of coordination among contractors and service contract, or poor communication between the design team and construction team. Among the advantages of review and manage the cost of rework include the 
following:

1. To improve the performance of the project is necessary to define the cost of rework and be collected and used to measure the cost impact of project failure.

2. Slight decrease in these costs can be substantial capital to maintain or profitable.

3. Pinpoint the origin of deviations and identifying the specific error will cause that failure of future projects and current project will not be repeated in the remaining tasks.

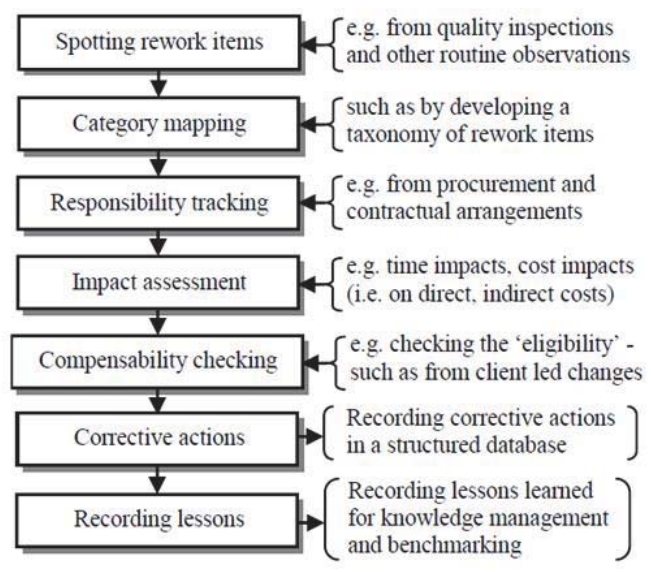

Figure 3. Management framework to control rework

Reduce the cost of rework is not easy. Another way to manage events of rework is using Pareto Logic that based on its argument only about $20 \%$ of cases of imminent failure for almost $80 \%$ of the cost of failure is considered and less time should be spent to check imbalances. Based on this reasoning, the failure can be easily identified and found a way to control and fix it.

\section{Results}

One of the serious shortcomings ofconstruction management is lack of attention to waste costs during construction. The construction industry was one of the private industry where customers are suppliers of capital. Unfortunately, in terms of cost control and identify cost waste no serious work have been done in our country. Rework while construction is the main reason of waste of resources. Today, some cases of rework have been accepted as an integral part of the construction activities. Contractors and project owners are trying to build buildings with the highest level of quality, but do not pay much attention to how to achieve this quality level. Mismanagement during the design and construction cause some activity repeated, or after completion of construction some of the shortcomings identified. This issue imposes a significant cost to the project. This article introduces the basics principles for project cost management in construction and manufacturing and introduced a framework for identifying rework factors root causes of it based on related factors to rework. Rework is one of the main problems in the field of construction and each construction project depending on implementation circumstances, has its own issues. Project Cost Management is one of the key tasks of the project managers and it would not be possible without the knowledge of cost structures and management techniques. The next step in the project cost management is awareness of the actual cost. Due to the nature of construction work, develop a framework that have all the costs is very difficult and at the same time vital issue. Knowing the actual cost of rework caused clarifying the rework issues and knowing rework issues cause to find key problems in manufacturing. Knowing this will avoid many future problems, and ultimately a significant portion of the capital will be maintained.

\section{References}

Central Bank of the Islamic Republic of Iran, www.cbi.ir.

A. Jarkas, C. Bitar, "Factors affecting construction labor productivity in Kuwait", ASCE Journal of Construction Engineering and 
Management, 138 (7) , 2012,pp 811-82.

Peter E.D., Lovea, Zahir Irani. "A project management quality cost information system for the construction industry". Information \& Management, 2003: pp.649-661.

MA Zhen, "Construction Cost Control under Engineering Quantity List Valuation" Construction Economy, vol. 313, 2008, pp.116-118.

G. Jergeas, J. Ruwanpura, Why cost and schedule overruns on mega oil sands projects?, Practice Periodical on Structural Design and Construction, 15 (1) , 2010, pp 40-43.

XU Bing, "Research on Target Cost Management of Construction Project with VBQ Based on EVM", International Conference on Information Management, 2009.

"A Guide to the Project Management Body of Knowledge , PMBOK Guide". Project Management Institute . 2004.

Antohie, E., "Classes of Construction Cost Estimates", Buletinul Institului Politehnic DIN IAŞI, 2009.

Hang Xiaojian and Ni Zirong, "Cost Management of Construction Project on BOQ Price Basis," Building Construction, vol. 27,.2005, pp. 67-71.

Love, P.E.D.,"Influence of Project Type and Procurement Method on Rework Costs in Building Construction Projects", Journal of Construction Engineering and Management, 2002, pp.18-29.

Kazaz A, Birgonul M, Uiuberyli S." Cost-based analysis of quality in developing countries: a case study of building projects". Build Environ, 2005;40:1356-65.

Palaneeswaran,E., "Reducing Rework to Enhance Project Performance Level", Seminar on Recent Developments in Project Management in Hong Kong, 2006.

CII, "An investigation of field rework in industrial construction", Construction Industry Institute, Austin,Texas,USA. Research Summery 153-11, 2001.

Fayek Aziz R., " Factors causing cost variation for constructing wastewater projects in Egypt", Alexandria Engineering Journal, Volume 52, Issue 1, 2013, pp 51-66.

Hwang B.G, Zhao X., " Investigating the client-related rework in building projects: The case of Singapore", International Journal of Project Management, Volume 32, Issue 4, 2014, pp 698-708. 